\title{
Logical Expressivism and Logical Relations
}

\author{
Lionel Shapiro
}

\section{Introduction}

A central motivation for expressivism about logic has been to avoid a view of logical vocabulary as serving to map the layout of a special domain of facts whose bearing on discursive practice remains mysterious. ${ }^{1}$ Logical expressivists adopt, instead, a pragmatist stance: they seek to explain the role of logical vocabulary in terms of discursive practice. In the form pioneered by Brandom and elaborated and extended by Peregrin, logical expressivism adopts a specific version of this stance. According to both philosophers, logical vocabulary lets us endorse broadly-speaking inferential relations, which are said to hold in virtue of socially instituted norms of discursive practice. Specifically, talk of consequence and incompatibility has such relations as its subject matter. And logical operators, such as conditionals and negation, give us an indirect way to endorse consequence and incompatibility relations.

In this chapter, I'll suggest an alternative version of logical expressivism. On my proposal, logical vocabulary doesn't serve to let us endorse discursive-practical relations. Rather, it serves to let us express discursive-practical attitudes. ${ }^{2}$ One upshot will be a different view of the importance of relational locutions such as "is a consequence of" and "is incompatible with." Brandom and Peregrin give these a central explanatory role: it is in terms of the socially-constituted relations attributed using consequence talk and incompatibility talk, they hold, that we must understand the expressive function of logical operators. According to the logical expressivism I'll propose, by contrast, the relational locutions have no such explanatory role. Indeed, I'll argue that the expressive role of the relational locutions undermines the plausibility of a reduction of logical relations to socially instituted norms of discursive practice.

In the second section, I begin by isolating two theses that are components of Brandomian logical expressivism: implicit-content expressivism and inferential-attitude expressivism. Focusing on conditionals, the third section critically examines the versions of implicit-content expressivism found in Brandom and Peregrin. The fourth section then proposes a version of inferential-attitude expressivism that differs from Brandom's. On the 
view I sketch there, the expressive role of a logical operator (here the conditional) is explained without invoking any logical relation (thus without invoking consequence). In the fifth section, I turn to logical relations, and give a deflationary account of the expressive role of our talk of consequence. The sixth section then argues that this account poses a challenge to an expressivism according to which the function of logical operators is to make explicit socially instituted logical relations.

\section{Two Components of Logical Expressivism}

Here's one way Brandom summarizes the substance of his logical expressivism:

Logic transforms semantic practices into principles [...]. [It] provid[es] the expressive tools permitting us to endorse in what we say what before we could endorse only in what we did [...]. (Brandom 1994, 402, emphasis added; cf. Peregrin 2008, 268; 2014, 187).

This characterization is ambiguous between two theses, both of which I believe Brandom intends to affirm. Each corresponds to a different way of identifying the kind of item which, in the absence of logical vocabulary, is endorsable only in practice, but which can also be endorsed by stating a principle once logical vocabulary is available.

- $\quad$ On one disambiguation, what can be endorsed implicitly is what Brandom calls a "claimable content" (for example, Brandom 1994, 330). To come to endorse a content "explicitly" (that is, "in what we say") is simply to come to assert the content.

- On another disambiguation, what can be endorsed implicitly is, broadly speaking, an inference. To come to endorse an inference "explicitly" (that is, "in what we say") is to come to endorse it by asserting some claimable content. ${ }^{3}$

We can thus formulate the theses combined in the quoted passage as follows:

Implicit-content expressivism: Logical vocabulary lets us endorse a content explicitly (that is, by asserting that content), a content which we already endorsed implicitly. Inferential-attitude expressivism: Logical vocabulary lets us endorse an inference explicitly (that is, by asserting a content), an inference which we already endorsed implicitly. 
My aim is to recommend a version of inferential-attitude expressivism. To set the stage, however, I'll first critically examine the versions of implicit-content expressivism found in Brandom and Peregrin.

\section{Making Explicit a Practice-Endorsed Content}

To make sense of implicit-content expressivism, we must answer two questions.

- What content does a given piece of logical vocabulary let us endorse explicitly?

- In what sense can this content be implicitly endorsed in what we do?

Consider the case of a conditional sentence. According to one way of answering these questions found in Brandom and Peregrin, the content a conditional sentence lets us endorse is a claim about an inferential relation. Specifically, it's a claim that there's a good inference from some premise to some conclusion. And there are two senses in which this claim can be implicitly endorsed. First, one can implicitly endorse the claim by treating premise and conclusion as inferentially related, even if in fact they aren't so related. (Someone might treat as good the inference from "There was just lightning" to "The gods are angry.") But according to both Brandom and Peregrin, a second kind of implicit endorsement is more basic. The claim that an inferential relation holds can be endorsed in one's social practice, in the sense that the practice can make that claim true by instituting the respective inferential relation.

Now the good inferences Brandom and Peregrin are concerned with aren't formally valid; they are "material inferences" such as that between "There was just lightning" and "There will soon be thunder." These are inferences whose goodness Brandom and Peregrin hold to be partly constitutive of the words "thunder" and "lightning" possessing their conceptual contents (Brandom 1998, 97-98; Peregrin 2014, 26). In what follows, I'll speak of material consequence instead of goodness of material inference. But Brandom and Peregrin understand material consequence in terms of norms of social practice that qualify as "inferential" in some suitably loose sense - they play some role in constraining, though not prescribing, a process of inferring. ${ }^{4}$

Understood this way, logical expressivism holds that in asserting a conditional, one states a claim about material consequence, where if one speaks truly this will be a claim one had previously endorsed in virtue of being a user of certain non-logical concepts, such as 
those of thunder and lightning. Numerous passages from Brandom support this interpretation:

$[T]$ he strategy pursued $[. .$.$] is to focus on the use of logical vocabulary to permit the$ explicit expression, as the content of sentences, of relations among sentences that are partly constitutive of their being contentful [...]. [Conditionals] permit the assertionally explicit expression of material-inferential relations. (Brandom 1994, 401-402)

Before introducing [the conditional], one can do something, namely endorse an inference. After introducing the conditional, one can now say that the inference is a good one. (Brandom 2000, 81; also 1994, 22, 108, 115; 2000, 21; 2010, 353; 2008b, 151)

Peregrin, too, speaks of a conditional operator as allowing what is already implicit in discursive practice to "find an explicit expression (in the form of a sentence stating that the inference holds)" (Peregrin 2014, 203).

Yet, understood this way, the expressivist's claim about conditionals can't be correct. First, as Brandom elsewhere notes, asserting a conditional isn't a matter of using explicitly normative vocabulary. To assert that if $p$ then $q$ isn't "to say that an act of inferring is permissible" (Brandom 2008a, 46 n). But it also isn't to affirm a "material-inferential relation" of consequence between the sentences " $p$ " and " $q$ " (or their contents), even if that relation is only ultimately understood in normative terms. The reason is a basic one. A conditional isn't a relational expression: it's a sentential operator, not a predicate.

I conclude that implicit-content expressivism should identify the content endorsed in practice as a conditional claim, not as a claim about a relation of consequence. On this view, a discursive practice - in virtue of instituting a material consequence relation — can implicitly endorse the claim that if there was just lightning, there will soon be thunder. Once practitioners come to deploy a conditional, they are then in a position to endorse this claim explicitly. In what sense, though, might a practice implicitly endorse a conditional claim?

An answer is suggested by Peregrin's discussion. Although a conditional doesn't state a claim about consequence, a discursive practice can nonetheless ensure that the conditional states a truth by making the corresponding consequence hold. Consider how Peregrin explains the conditional's expressive role. He writes: "We need a sentence which expresses the fact that $B$ is inferable from $A$ " (Peregrin 2014, 187). Since he has in mind a conditional sentence, I'll assume that “expressing” the fact about inferability doesn't mean stating that relational fact itself, but rather stating a suitably related conditional content. He continues: 
"But what does it take for a sentence [of the object language] to express this? Presumably to be true if and only if $B$ is inferable from $A . "$

We now have a way to understand a conditional $A \Rightarrow B$ as stating a claim endorsed by the discursive practice in which sentences $A$ and $B$ are used: ${ }^{6}$

(*) $\quad A \Rightarrow B$ states a claim that's true if and only if $B$ is a material consequence of $A .^{7}$

Recall that Peregrin is interested in a consequence relation that's meaning-constitutive. Suppose that $\Rightarrow$ meets his condition $(*)$ for expressing such consequence. Then it had better not be the conditional of classical or intuitionistic logic. Where $\rightarrow$ is one of those conditionals, $A \rightarrow B$ will be true if $B$ is true. But Peregrin isn't willing to allow that each true sentence is a meaning-constitutive consequence of every other sentence (Peregrin 2014, 196197). So the conditional $\Rightarrow$ that "does the expressive work" by satisfying $(*)$ must be a different one. Perhaps, he suggests, it will be a strict conditional definable using a modal operator, so that $A \Rightarrow B$ is $\square(A \rightarrow B) .^{8}$ In what follows, I'll assume that the conditional operator under discussion satisfies condition $(*){ }^{9}$

Drawing on Peregrin, I have arrived at what I think is the best formulation of implicitcontent expressivism about conditionals. In at least two ways, this view gives priority to consequence talk over conditionals. First, the purpose of the conditional is one that would be served more perspicuously using a consequence predicate. ${ }^{10}$ This calls to mind Carnap's account of the relation between claims of logical consequence (" $L$-consequence") and corresponding object-language conditionals (Carnap 1934, § 63, § 69). According to Carnap, a language can have a binary sentential operator " $\operatorname{LImp}$ " such that " $\operatorname{LImp}(A, B)$ " is inferentially equivalent to the consequence predication " ' $B$ ' is an $L$-consequence of ' $A$ '." Yet the former conditional is said to be a "quasi-syntactical sentence," whose role would be played more perspicuously by the latter, its “correlated syntactical sentence.” We can put this in Carnap's "material mode": such a conditional serves as a convenient means for talking indirectly about consequence. Likewise, according to the content-expressivist version of logical expressivism under discussion, conditionals serve as a convenient means for talking indirectly about material consequence. Here's another way to explain how consequence locutions enjoy priority over conditional operators according to Brandom and Peregrin: consequence talk plays an explanatory role in their accounts of the function of the corresponding conditional operator.

In the rest of the chapter, I'll argue against giving consequence locutions priority over 
operators. Let's start by considering how Brandomian logical expressivism understands material consequence as something that can bear explanatory weight: namely, as a relation that obtains in virtue of a structure of norms governing a discursive practice. Suppose we grant a sense (however vague or context-sensitive) in which "There will be thunder soon" is a consequence of "There is lightning now." Should we agree with Brandom and Peregrin that this holds in virtue of norms of social practice?

For an initial sense of why I think we should be skeptical, it should help to compare the relation of material consequence with the property of truth. Unlike Brandom, Peregrin accepts an analysis of truth in terms of meaning-constitutive rules (Peregrin 2014, 83, 236). He cites with approval Sellars' claim that to be true is "to be assertible [...] in accordance with the relevant semantical rules, and on the basis of such additional [...] information [namely, about empirical circumstances] as these rules may require" (Sellars 1967, 101). Against such views, I would urge, adapting a remark by Quine $(1953,437)$, that the "notion of truth is a far less dubious starting point" than any notion of semantic rule in terms of which one might seek to explain truth. ${ }^{11}$ As I'll discuss later, Quine's doubts are substantiated by his subsequent "deflationary" account of the expressive function served by a truth predicate. ${ }^{12}$

Now I believe that what I've said about truth and semantic correctness goes equally for material consequence and inferential correctness. The claim that "There will be thunder soon" follows from "There is lightning now" strikes me as a far less dubious starting point than any claim about what's correct or incorrect according to socially instituted inferential norms. And just as in the case of truth, I'll argue that the reason can be seen once we examine the expressive role of the predicate "follows from" (or "is a material consequence of"). For the time being, I hope to have made it worth asking this chapter's key question, which is as follows. Can there be a version of logical expressivism that not only follows Brandom in rejecting explanations of truth in terms of social-practical correctness, but also rejects explanations of material consequence in terms of social-practical correctness? ${ }^{13}$

\section{Making Explicit One's Endorsement of an Inference}

For this purpose, I turn now to a different way of understanding how logical vocabulary makes explicit something implicit in what one does. According to inferential-attitude expressivism, what asserting a conditional makes explicit is one's endorsing of an inference. This is certainly a claim Brandom makes: 
Saying that if something is copper then it conducts electricity is a new way of doingby saying - what one was doing before by endorsing the material inference from "That is copper" to "That conducts electricity" [...]. Where before one could only in practice take or treat inferences as good or bad, after the [...] introduction of conditionals one can endorse or reject the inference by explicitly saying something [...]. (Brandom 2008a, 45-46).

[Introducing conditionals] will let one say something, the saying of which is taking some inferences to be good and other ones not good (Brandom 2008a, 47). ${ }^{14}$

Understood this way, logical expressivism explains the role of conditionals using a sense of "express" distinct from what Sellars calls the "logical (or semantical) sense" in which what is expressed is a content (Sellars 1969, 521). Rather, the relevant sense of "express" is a pragmatic one. ${ }^{15}$ By asserting a conditional that semantically expresses a certain content, one pragmatically expresses one's endorsing of an inference. Brandom points out the connection to Ryle's account of conditionals as "inference licenses" (Brandom 2008a, 104; Ryle [1950] 2009). ${ }^{16}$

In explaining the function of some target vocabulary in terms of a pragmatic sense of expressing, inferential-attitude expressivism stands in the tradition Price (2011a) calls "Humean expressivism" (and also resembles the "neo-expressivism" of Bar-On 2004). ${ }^{17}$ Compare a Humean expressivist who holds that when one asserts that a thing is good, what one is doing is expressing one's valuing of it. Such a theorist isn't explaining the assertion as the endorsement of a content whose truth is determined by facts about what the asserter, or anyone else, values (or should value). Similarly, if asserting a conditional expresses one's endorsing of an inference, this needn't mean that the conditional's truth is determined by facts about the inferential attitudes anyone has (or should have).

However, Brandom's version of inferential-attitude expressivism won't do for my purposes. The problem concerns the practical attitudes expressed by conditionals. According to Brandom, to endorse an inference - to "treat [it] as good"- - is to attribute to practitioners that constellation of normative statuses in which, on Brandom's theory, material consequence consists. Going this route would open up inferential-attitude expressivism to the doubts I raised earlier. But I see no reason why an explanation of the role of conditionals in endorsing inferences must describe the asserter of a conditional as implicitly affirming any relation of consequence. 
What, then, do I mean by endorsing an inference? Here's a rough sketch. Following Brandom (1994), I'll conceive of discursive practice as a "game of giving and asking for reasons" in which practitioners undertake commitments to defend their assertions in response to appropriate challenges. Again like Brandom, I propose that the conditional I'm describing makes explicit something essential to participation in any such game (Brandom 2008a, 53, 26). In asserting "If $p$, then $q$," I suggest, a speaker of English (here "the subject") expresses dispositions that are manifested as follows in an exchange with an interlocutor: ${ }^{18}$

- when an interlocutor has challenged the subject's assertion that $q$, the subject treats her own adducing of a warranted assertion that $p$ as meeting that challenge, ${ }^{19}$

- when the subject has challenged an interlocutor's assertion that $q$, she treats that interlocutor's adducing of a warranted assertion that $p$ as meeting her challenge, ${ }^{20}$

- when an interlocutor has asserted that $p$, the subject treats her own rejection of the claim that $q$ as challenging that interlocutor's assertion, and

- $\quad$ when the subject has asserted that $p$, she treats an interlocutor's rejection of the claim that $q$ as challenging her own assertion.

Furthermore, in virtue of asserting the conditional, the speaker licenses hearers to do likewise, on the asserter's authority. Crucially, however, this needn't mean that the asserter regards manifesting the above-described dispositions as in any sense correct for a participant in the linguistic practice.

Consider one of Brandom's favorite examples (Brandom 1994, 634). Suppose I assert, speaking about a certain tractor, "If this tractor is completely green, then it is made by John Deere." And suppose that, in an unrelated conversation, Barack Obama asserts that the tractor in question is completely green. I need not, merely in virtue of having asserted my conditional, take it to be correct, in any sense, for Obama to treat his interlocutor's rejection of the claim that the tractor is made by John Deere as a way to challenge his assertion. To see this point it should help to compare assertion in general. On the Brandomian view adopted here, in asserting that $p$, I license my hearers to assert that $p$. But that doesn't give rise to any sense in which I must regard the proposition that $p$ as correctly assertible by speakers of my language.

I have now sketched an account of the expressive role of a conditional that agrees with 
Brandom and Peregrin in viewing the conditional as making explicit something implicit in any discursive practice. To flesh out this proposal, I would need to discuss other logical operators, but space doesn't allow that here. Instead, I'll turn to logical relations, specifically material consequence.

\section{The Function of Consequence Talk}

Unlike Brandomian logical expressivism, the approach I've proposed doesn't start with a relation of material consequence, instituted by a social practice. What, then, can I say about material consequence, about the sense in which "There will soon be thunder" follows from "There was just lightning”?

Ryle, whose view of conditionals as inference licenses we have been developing, asks: "But just how does the [material] validity of the argument require the truth of the hypothetical statement [that is, the conditional"]?" (Ryle [1950] 2009, 247). Though he never explicitly answers his question, his idea seems to be that for a single-premise inference to be correctly performed (the "conclusion [...] legitimately drawn from the premiss"), the conditional that would license it must be true. I'll argue that we can maintain a Ryleian view of conditionals without understanding validity/consequence in terms of correctness of inference. This requires a radically different answer to Ryle's question.

Here I think the key move is to turn away from asking what material consequence consists in, and instead pose the more expressivist question: what is the expressive role of consequence locutions? What purpose do they serve in our linguistic practice? ${ }^{21}$ To answer this, let me start by considering locutions that express a relation of single-premise material consequence between claimable contents. Elsewhere (Shapiro 2011), I have argued that there would be no need for consequence talk if it weren't for our need to express certain kinds of generalizations. ${ }^{22}$ In place of "The claim that there will soon be thunder is a material consequence of the claim that there was just lightning," we could use a conditional "If there was just lightning, then there will soon be thunder." What consequence locutions allow us to do is to achieve the effect of quantifying into sentence position by instead quantifying over contents or their bearers. Thus we can formulate generalizations such as

(a) She denied a material consequence of something he asserted.

\footnotetext{
" [Note: in the published version, the brackets inadvertently contain 'that is conditional'.]
} 
(b) If a claim is a material consequence of each of two other claims, then it is a material consequence of their disjunction.

Claim (a) can take the place of an existential generalization over all sentences of the form "He asserted that $p$, and she denied that $q$, and if $p$ then $q$." Claim (b) can take the place of a universal generalization over all sentences of the form "If it's the case that if $p$ then $r$ and it's also the case that if $q$ then $r$, then it's the case that if $p$ or $q$ then $r . "$

Next, consider multi-premise consequence locutions. Again, if it weren't for our interest in expressing generalizations, we could make do with conditionals with conjunctive antecedents. In place of "The claim that a rainbow can be seen is a joint material consequence of the claims that it's raining and that the sun is shining" we could say "If it's raining and the sun is shining, then a rainbow can be seen." But multi-premise consequence talk lets us formulate lots of useful generalizations, which we can then subject to critical assessment. Here are three examples:

(c) What Brandom claims follows from something said by Kant together with something said by Sellars.

(d) One ought to believe the joint consequences of any set of claims one believes.

(e) If claim $Q$ follows from claim $P$ together with the claims in set $X$, and $P$ follows from the claims in set $Y$, then $\mathrm{Q}$ follows from the claims in the union of $X$ and $Y$. (This is a version of the Cut rule. $)^{23}$

Let me contrast this proposal with what Peregrin says about the relation between conjunction and multi-premise consequence. According to him, an important expressive role of conjunction lies in allowing us to talk indirectly about what follows from a number of premises taken together. By asserting the conditional $(A \wedge B) \Rightarrow C$, I can make explicit what's implicit in (the claim expressed by) $C$ 's being a consequence of (the claim expressed by) $A$ taken together with (the claim expressed by) $B \cdot{ }^{24}$ Peregrin describes conjunction as an operator that serves as "amalgamator" for premises. It does so by satisfying the principle

(Am) For all sentences $A, B$, and $C$, and every set $X$ of sentences, $X, A \wedge B \vdash C$ if and only if $X, A, B \vdash C$.

Here $\vdash$ is used to express the relation of material consequence that can obtain between a set of premises and a conclusion.

Peregrin also suggests a second way conjunction makes explicit structural features of 
consequence. He says that it "marks" or "reveals" a relational feature a sentence possesses considered as an element of an "inferential structure," namely the feature of being an “inferential supremum." Here's one way of understanding Peregrin's claim: by asserting the biconditional $(A \wedge B) \Leftrightarrow C$, I make explicit in the form of an assertion what's already implicit in $C$ 's being an inferential supremum for the sentences $A$ and $B$. This explicitation will be possible provided conjunction satisfies the principle

(Sup) For all sentences $A$ and $B$ and every set $X$ of sentences, $X \vdash A \wedge B$ if and only if both

$$
X \vdash A \text { and } X \vdash B \text {. }
$$

According to Peregrin, then, Došen $(1989,366-367)$ is right that conjunction as well as the conditional are operators that serve as "a kind of substitute in the object language" for talk of consequence and its "structural features.", 25

My proposal inverts the perspective of Došen and Peregrin. I have argued that our talk of consequence (and its structural features) has as its expressive role allowing us to formulate generalizations over sentences involving certain operators. In particular, the expressive role of talk about a claim being the consequence of several premises taken together lies in allowing generalization over conditionals with conjunctions as antecedents. The biconditional $(\mathrm{Am})$ doesn't explain the expressive role of conjunction. Instead, it explains how the multi-premise consequence locution $X \vdash A$ can play its expressive role. ${ }^{26}$ The biconditional (Sup) then makes use of this expressive role.

Let me pause to deflect an objection. Since I'm characterizing the role of consequence talk as lying in how it lets us generalize over conditionals, it would be accurate to say, using Brandom's words, that my proposal "trades primitive goodnesses of inference for the truth of conditionals." And that's precisely what Brandom says is done by the "formalist approach to inference" he himself convincingly criticizes (Brandom 1994, 98, 112). But my proposal doesn't in fact involve the formalist idea that's the target of Brandom's criticism. This is the idea that the material entailment from "There was just lightning" to "There will soon be thunder" must be accounted for in terms of a formal consequence involving as an additional premise the conditional "If there was just lightning then there will soon be thunder." On the current proposal, the connection between conditionals and inferences isn't explained in terms of the role of conditionals as premises in inferences. Rather, just as on Brandom's own Ryleian approach, conditionals serve to let us express our endorsing of inferences. 


\section{Consequence as a Merely Logical Relation}

I can now explain why I'm skeptical about a logical expressivism according to which logical operators serve to indirectly talk about material consequence, understood as a socially instituted relation. This is because the above explanation of the expressive role of consequence talk gives reason to doubt that consequence is such a relation.

Here I draw on an analogy with deflationism about truth proposed in Shapiro (2011). According to the brand of deflationism I find attractive, the functions that give the predicate "true" its raison d'être are very limited.

- We use "true" to semantically express generalizations that achieve the effect of quantification into sentence position, for example, "None of his claims about Russia are true." 27

- We use "true" to pragmatically express something essential to our ability to ascribe claimable contents in the first place. That is our disposition to conclude that $p$ on the basis of our taking our informant to have asserted the claim that $p$, a disposition we express when we assert "What she claimed is true.",28

To understand how the predicate "true" serves each these functions, it's enough to know that for all sentences $S$ in our language, freestanding or logically embedded,

(T) $S$ can be replaced by "the claim that $S$ is true," or vice versa, with no effect on the game of giving and asking for reasons.

I agree with deflationists, including Brandom, that there's little reason to think $(T)$ requires that there will be any features shared by all and only truths that explain their being true. In particular, there seems no reason to expect a connection between a predicate's behaving according to $(T)$ and its attributing the property of being correctly assertible according to certain socially-instituted rules. There's no reason to think the "logical property" of truth (Horwich 1998, 37) will turn out to be a socio-linguistic property. ${ }^{29}$ As for the predicate "is a material consequence of," I've argued that its role can be completely understood in terms of how consequence talk allows expression of generalizations over conditionals. To understand how “is a consequence of" serves this function, it's enough to know that for all sentences $S$ and $R$ in our language, freestanding or logically embedded, 
(C) "If $S$ then $R$ " can be replaced by "the claim that $R$ is a material consequence of the claim that $S$," or vice versa, with no effect on the game of giving and asking for reasons.

Again, there seems no reason to expect any connection between a predicate's behaving according to $(C)$ and its attributing a socially instituted normative relation. Nothing about this account of how "is a material consequence of" serves its function suggests there will be features shared by just the pairs of claims that stand in the relation of consequence that explain their standing in that relation. ${ }^{\dagger}$ Material consequence appears to be a "merely logical relation" rather than a socio-linguistic one. ${ }^{30}$ Furthermore, though I can't argue this here, I would suggest that the same holds for material incompatibility.

\section{Conclusion}

As I hope to have shown, logical expressivism as advocated by Brandom and Peregrin combines two important lines of thought. The first is familiar from discussions of logic, the second from areas such as metaethics.

(1) Logicians talk about which features of object language expressions, as specified by the theorist using a metalanguage, can be "expressed in the object language." For example, it's said that for many three-valued logics, the property of being untrue fails to be expressed by any operator.

(2) "Expressivists" about normative and modal locutions stress "the practical role they play in our lives" (Price 2011a). For example, normative vocabulary may let us express our plans and epistemic modals let us express our leaving possibilities open in inquiry and action (Gibbard 2003; Yalcin 2011).

As Brandom and Peregrin develop logical expressivism, it contributes to tradition (2) by exploiting tradition (1). Peregrin writes that "logical vocabulary appears as a means of "internalizing the meta." It allows us to say within a language what can otherwise be said only about a language-i.e. within a metalanguage" (Peregrin 2008, 269). ${ }^{31}$

I have argued for an understanding of logical vocabulary that contributes to tradition (2) independently of (1). This is a logical expressivism on which logical operators don't serve

\footnotetext{
${ }^{\dagger}$ [Note: the published version of this sentence inadvertently contains text from an earlier draft.]
} 
to internalize features of a discursive practice. To be logical expressivists, we shouldn't say that logical operators serve to express in the object language the obtaining of logical relations. Instead, we should adopt the deflationist strategy of explaining talk of logical relations as a mere device of generalization, and focus attention on explaining the role of logical operators in terms of the discursive attitudes these let us express. ${ }^{32}$

\section{Notes}

${ }^{1}$ See esp. Peregrin $(2014,215 ; 2000,87-88)$ and Brandom (1994, 108; 2000, 19 ff).

${ }^{2}$ As will be explained, the logical expressivism I'm proposing is in the tradition called "Humean expressivism" by Price (2011a).

${ }^{3}$ The ambiguity sometimes leads to conflation. Thus Brandom $(2002,9)$ explains that on his "expressive view of the function of logic, the task characteristic of logical locutions as such is to let us say, in the form of explicit claims, what otherwise we could only $d o$-namely endorse some material inferential relations and reject others." Yet "endorse [...] inferential relations" isn't something that we can "say" as well as "do." Rather, we can come to do this by asserting something else, a claimable content.

${ }^{4}$ Brandom characterizes "relations of material consequence and incompatibility" as "inferential relations" (Brandom 2011, 32), and Peregrin says that "to be correctly inferable from is nothing other than to be a consequence of" (Peregrin 2014, 152-153). He explains that the "crucial role of rules with respect to our linguistic conduct is not prescriptive [...] but rather restrictive; rules tell us what not to do, what is prohibited" (Peregrin 2014, 72). In a sympathetic reconstruction of Hegel's thought, Brandom too identifies material consequence with inferential propriety: "What it is for one proposition to stand in a relation of implying or entailing another just is for certain inferential moves and not others to be correct or appropriate." These correctnesses "constrain what we should do without determining it" (Brandom 2002, 192, 194).

${ }^{5}$ Brandom sometimes says conditionals state relations between claimable contents rather than content-bearers: "Conditionals assert explicitly that one thing that can be said follows from another thing that can be said, that the one is a consequence of the other" (Brandom 2008a, 46 n; also 1994, xix; 2011, 208 n).

${ }^{6}$ Here, as in other contexts where the language being considered is a formally regimented one 
(containing, for example, arrows), italics serve as my device of quasi-quotation. Where the language is English, ordinary quotation marks will serve the same purpose.

${ }^{7}$ If facts about material consequence are contingent, we should additionally require that the biconditional $(*)$ would hold in any possible circumstance. Peregrin appears to deny that material consequence is contingent (Peregrin 2014, 187), but he may have in mind a relation between contents, not content-bearers (cf. Peregrin 2014, 249 n. 12).

${ }^{8}$ Peregrin also writes that if $A \rightarrow B$ isn't what "does the expressive work," that work may instead be done by $\vdash A \rightarrow B$. Elsewhere, he defends this by saying that "the counterpart of necessary truth within the structure [on which $\vdash$ is defined] is clearly theoremhood" (Peregrin $2014,187)$. Yet $\vdash A \rightarrow B$ isn't a sentence in the language of $A$ and $B$; theoremhood of $A \rightarrow B$ would presumably be expressed in that language using $\square(A \rightarrow B)$. Anticipating logical expressivism, Došen $(1989,375 ; 1980,284-285)$ gives a similar explanation of what it means for a conditional $\rightarrow$ to "serve to make explicit" a consequence relation that's "implicit in the activity of making deductions." He too argues that this is captured by the equivalence of $\vdash A$ $\rightarrow B$ with $A \vdash B$. However, Došen's explanation of how the equivalence yields an "analysis" of $\rightarrow$ in terms of $\vdash$ doesn't help me understand what he means by making explicit.

${ }^{9}$ Interestingly, such a $\Rightarrow$ won’t count as what Peregrin calls a "deductor." A deductor $\triangleright$ is required to satisfy the condition that $X, A \vdash B$ if and only if $X \vdash A \triangleright B$. Assuming reflexivity and weakening, as Peregrin does, this yields that $B \vdash A \triangleright B$. Suppose $B$ is true. If the consequence-expressing $\Rightarrow$ is a deductor, then $A \Rightarrow B$ is true, which by (*) implies that $B$ is a consequence of $A$, for any $A$. But Peregrin wouldn't concede this when $B$ is a contingent truth. ${ }^{10}$ See Weiss $(2010,249)$, who however assumes that such a predicate would have to belong to a metalanguage distinct from the object language the predicate is used to talk about. One ground for that conclusion might be the threat of a form of Curry's paradox - for a discussion and response, see Shapiro (2011). Even if the consequence predicate did have to belong to a distinct metalanguage, however, the metalanguage could still contain the object language whose inferential relations it describes.

${ }^{11}$ Quine's target is the notion of analyticity.

${ }^{12}$ Quine (1970). Brandom's position on truth is deflationary as well (Brandon 1994, chap. 5). For critiques of Sellars' definition of truth, see Williams (2016) and Shapiro (Forthcoming). 
${ }^{13}$ I don't mean to deny that there are normative facts about inference-no doubt there are several sorts of inferential propriety. Rather, I'm skeptical that there is any close connection between such goodnesses and a relation of material consequence that holds whenever a corresponding conditional is true.

${ }^{14}$ What looks like implicit-content expressivism may sometimes be a notational variant of inferential-attitude expressivism. Consider the claim that in endorsing some inference, someone implicitly endorsed the claim that if $p$ then $q$. Understood one way, this just means they did something that could also be done by asserting that if $p$ then $q$. This may explain why Brandom, immediately following one of the above statements of inferential-attitude expressivism, adds this statement of implicit-content expressivism: "What the conditional says explicitly is what one endorsed implicitly by doing what one did" (Brandom 2008a, 46).

${ }^{15}$ On semantic and pragmatic senses of “express," see also Bar-On (2004).

${ }^{16}$ Brandom has recently criticized Sellars' accounts of ontological and modal discourse for "running together pragmatic issues, of what one is doing in saying something, with semantic issues of what is said thereby" (Brandom 2015, 267, 190). I am proposing that logical expressivism too benefits from the kind of separation Brandom urges.

${ }^{17}$ Price applies this approach to negation (Price 2011b, 69-72) and conditionals (Price 2011b, 83). He argues that Humean expressivism is compatible with, indeed supports, Brandom's account of discursive practices. The logical expressivism I will recommend here is a Humean expressivism that conflicts with Brandom's views. See Field (2015) for a very different version of Humean expressivism applied to an item of logical vocabulary, namely the predicate "logically valid."

${ }^{18}$ The asserter expresses these dispositions in the sense that the act of asserting the conditional has as a function to convey to hearers that the speaker is so disposed.

${ }^{19}$ Here the assertion that $p$ may be by the speaker herself or by someone else, though in the former case only when " $p$ " is distinct from " $q$."

${ }^{20}$ Again, the assertion that $p$ may be by the interlocutor or by some other speaker, though in the former case only when " $p$ " is distinct from " $q$."

${ }^{21}$ Ryle, by contrast, writes: "I have said nothing about statements of the kind ' $p$ ' entails ' $q$ ' or ' $q$ ' does (or does not) follow from ' $p$.' Such locutions are used (roughly) not by the players in the field but by the spectators, critics and selectors in the grandstand. They belong to the talk 
of logicians, cross-examiners, and reviewers" (Ryle [1950] 2009, 259-260). If I am right, examining such talk is key to answering Ryle's question, from the grandstand, about how an argument's validity requires the truth of the corresponding conditional.

${ }^{22}$ That paper concerns logical consequence, but the application to material consequence is immediate.

${ }^{23}$ In Shapiro (2015), I argue that it's in claims like these that consequence talk comes into its own as an expressive resource.

${ }^{24}$ Peregrin (2014, 189-193, 201-203); see already Peregrin (2003; 2008). Brandom makes the same point: "Indeed, I would say that making it possible to make explicit multipremise inferences is the principal expressive role characteristic of conjunction" (Brandom 2010, 354).

${ }^{25}$ Depending on the structural features of $\vdash$, a connective $\wedge_{a m}$ serving the expressive role underwritted by $(\mathrm{Am})$ may exhibit a different logical behavior from a connective $\bigwedge_{\text {sup }}$ serving the expressive role underwritten by (Sup). For example, if $\vdash$ is noncontractive, $A \vdash A \wedge_{\text {sup }} A$ but $A \nvdash A \wedge_{a m} A$. Here $\wedge_{a m}$ is so-called "multiplicative" conjunction and $\bigwedge_{\text {sup }}$ is "additive" conjunction. See Sambin et al. (2000).

$\left.{ }^{26} \mathrm{Am}\right)$ only suffices to explain this for finite $X$. The expressive role of infinite-premise consequence locutions can then be understood in terms of a truth predicate: they allow us to generalize over conditionals whose antecedents say that all the members of a set are true.

${ }^{27}$ This is the function pointed out by Quine $(1970,10-12)$.

${ }^{28}$ I have argued elsewhere that this non-Quinean idea is suggested by Sellars' discussions of the function of content ascriptions (Shapiro 2014).

${ }^{29}$ Here I've been talking about the truth of claimable contents (or propositions). The truth of utterances, or sentences-in-context, won't be a merely logical property: it will be the semantico-logical property of expressing a true content.

${ }^{30}$ One might wonder in what sense, on the view I've criticized, material consequence between propositional contents (rather than linguistic content-bearers) is a socio-linguistic matter. An answer would be that constitutive of the identity of such contents are the inferential norms a practice would have to display in order to express those contents. This is compatible with holding that the material consequence relation between the contents obtained prior to the existence of any such practice. 
${ }^{31}$ Another position of this sort is Thomasson's explanation of the expressive function of modals like "necessarily" (Thomasson 2013). She holds that modals "convey semantic rules in the object language, under conditions of semantic descent, rather than stating them in a metalanguage" (Thomasson 2013, 148). And the modal sentence that conveys such a rule is said to be correctly asserted just in case the rule in fact holds of the language.

${ }^{32}$ I am very grateful to Jaroslav Peregrin for discussion and criticism over the years. For helpful feedback, I thank the participants of the conference Why Rules Matter, especially Pavel Arazim and Matej Drobňák. Part of this work was done while I was supported by a fellowship from the Alexander von Humboldt Foundation.

\section{References}

Bar-On, Dorit. 2004. Speaking My Mind: Expression and Self-Knowledge. Oxford: Oxford University Press.

Brandom, Robert. 1994. Making It Explicit: Reasoning, Representing, and Discursive Commitment. Cambridge, MA: Harvard University Press.

Brandom, Robert. 2000. Articulating Reasons: An Introduction to Inferentialism. Cambridge, MA: Harvard University Press.

Brandom, Robert. 2002. Tales of the Mighty Dead: Historical Essays in the Metaphysics of Intentionality. Cambridge, MA: Harvard University Press.

Brandom, Robert. 2008a. Between Saying and Doing: Towards an Analytic Pragmatism. Oxford: Oxford University Press.

Brandom, Robert. 2008b. "Responses.” Philosophical Topics 36 (2): 135-155.

Brandom, Robert. 2009. Reason in Philosophy: Animating Ideas. Cambridge, MA: Harvard University Press.

Brandom, Robert. 2010. “Reply to Bernhard Weiss's 'What is Logic?'.” In Reading Brandom, edited by Bernard Weiss and Jeremy Wanderer. Abingdon: Routledge.

Brandom, Robert. 2011. Perspectives on Pragmatism: Classical, Recent, and Contemporary. Cambridge, MA: Harvard University Press.

Brandom, Robert. 2015. From Empiricism to Expressivism: Brandom Reads Sellars. 
Cambridge, MA: Harvard University Press.

Carnap, Rudolf. 1934. Logische Syntax der Sprache. Berlin: Springer.

Došen, Kosta. 1980. "Logical Constants: An Essay in Proof Theory." PhD diss., University of Oxford.

Došen, Kosta. 1989. "Logical Constants as Punctuation Marks.” Notre Dame Journal of Formal Logic 30 (3): 362-381.

Field, Hartry. 2015. "What is Logical Validity?” In Foundations of Logical Consequence, edited by Colin Caret and Ole Hjortland, 33-70. Oxford: Oxford University Press.

Gibbard, Allan. 2003. Thinking How to Live. Cambridge, MA: Harvard University Press.

Horwich, Paul. 1998. Truth. $2^{\text {nd }}$ ed. Oxford: Oxford University Press.

Peregrin, Jaroslav. 2000. “The 'Natural' and the 'Formal'.” Journal of Philosophical Logic 29 (1): 75-101.

Peregrin, Jaroslav. 2003. "Logic as 'Making It Explicit'.” In Logica Yearbook 2003, edited by Libor Běhounek. Prague: Filosofia.

Peregrin, Jaroslav. 2008. "What is the Logic of Inference?” Studia Logica 88 (2): 263-294.

Peregrin, Jaroslav. 2014. Inferentialism: Why Rules Matter. Basingstoke: Palgrave Macmillan.

Price, Huw. 2011a. "Expressivism for Two Voices." In Pragmatism, Science and Naturalism, edited by Jonathan Knowles and Henrik Rydenfelt. Frankfurt a.M.: Peter Lang.

Price, Huw. 2011b. Naturalism Without Mirrors. Oxford: Oxford University Press.

Quine, Willard Van Orman. 1953. "Mr. Strawson on Logical Theory.” Mind 62 (248): 433451.

Quine, Willard Van Orman. 1970. Philosophy of Logic. Cambridge, MA: Harvard University Press.

Ryle, Gilbert. 2009. ““'If,' 'So,' and 'Because'.” In Collected Essays 1929-1968, edited by Gilbert Ryle and Julia Tanney, 244-260. Abingdon: Routledge. Original edition, 1950.

Sambin, Giovanni, Giulia Battilotti, and Claudia Faggian. 2000. "Basic Logic: Reflection, Symmetry, Visibility.” Journal of Symbolic Logic 65 (3): 979-1013.

Sellars, Wilfrid. 1967. Science and Metaphysics: Variations on Kantian Themes. London: 
Routledge and Kegan Paul.

Sellars, Wilfrid. 1969. "Language as Thought and as Communication.” Philosophy and Phenomenological Research 29 (4): 506-527.

Shapiro, Lionel. 2011. "Deflating Logical Consequence.” Philosophical Quarterly 61 (243): $320-342$.

Shapiro, Lionel. 2014. "Sellars on the Function of Semantic Vocabulary." British Journal for the History of Philosophy 22 (4): 792-811.

Shapiro, Lionel. 2015. "Naive Structure, Contraction and Paradox.” Topoi 34 (1): 75-87.

Shapiro, Lionel. Forthcoming. "Sellars, Truth Pluralism, and Truth Relativism.” In Sellars and Twentieth-Century Philosophy, edited by Stefan Brandt and Anke Breunig. London: Routledge.

Thomasson, Amie. 2013. "Norms and Necessity." Southern Journal of Philosophy 51 (2): $143-160$.

Weiss, Bernhard. 2010. “What is Logic?” In Reading Brandom: On Making It Explicit, edited by Bernhard Weiss and Jeremy Wanderer, 247-261. Abingdon: Routledge.

Williams, Michael. 2016. "Pragmatism, Sellars, and Truth.” In Sellars and his Legacy, edited by James O'Shea, 223-260. Oxford: Oxford University Press.

Yalcin, Seth. 2011. "Nonfactualism about Epistemic Modality." In Epistemic Modality, edited by Andy Egan and Brian Weatherson, 295-332. Oxford: Oxford University Press. 